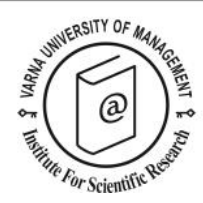

\title{
A collaborative approach in tourism planning: The case of Tuscany region
}

\author{
Elena Gori ${ }^{1}$, Silvia Fissi ${ }^{2 *}$ and Alberto Romolini ${ }^{3}$
}

\begin{abstract}
${ }^{1}$ Department of Business and Economics, University of Florence, Italy. E-mail: elena.gori@unifi.it
${ }^{2}$ Department of Business and Economics, University of Florence, Italy. E-mail: silvia.fissi@unifi.it

3 Faculty of Economics, International Telematic University Uninettuno, Rome, Italy. E-mail:

a.romolini@uninettunouniversity.net
\end{abstract}

${ }^{*}$ Corresponding author

\begin{abstract}
Community collaboration and participation are necessary to strengthen the effectiveness of tourism policy. This article aims to examine the tourism planning activity of public administration in fostering a collaborative approach. The article contributes to the debate on collaborative approach in tourism from the perspective of public administration. The research uses a case study and examines how Tuscany region applies a collaborative tourism planning approach using the Habermasian framework. Results underline the fundamental role of local government can be strengthened by an extensive stakeholder engagement process able to encourage broad representation and trust of stakeholder interest about public policies. Moreover, the collaborative approach by mixing the different point of view of stakeholders, produces a range of positive outcomes and increases the efficacy of tourism policies. However, the realization of the "ideal speech situation" is very difficult and may be undermined by the threatens highlighted in the study, such as the lack of financial resources, the claim to more homogeneous policies to increase tourism trends, the need to improve trust and collaboration between public and private, the difficulties in maintaining high level of attention and the widespread scepticism about the capability of public entities to understand priorities in defining tourism policies.
\end{abstract}

Key words: tourism planning, collaborative planning, ideal speech situation, Tuscany tourism, Habermas.

Citation: Gori, E., Fissi, S. and Romolini. A. (2021). A collaborative approach in tourism planning: The case of Tuscany region. European Journal of Tourism Research 29, 2907. 


\section{Introduction}

Tourism provides advantages for a community by increasing economic benefits, improving the community infrastructure and quality of life, and increasing employment rates (Hatipoglu et al., 2016). According to the UNWTO (2019), total international tourism exports increased by $4 \%$ to reach 1.7 USD trillion and tourist arrivals grew by $5 \%$. This trend is of interest here in southern and Mediterranean Europe, with Italy, Greece, Portugal and Croatia showing a particularly good performance.

Two challenging theoretical areas in the social science literature have arisen in public tourism planning in the last few years (Petrova and Hristov, 2016). First, one body of study has analysed the socio-political context of tourism planning (Hanrahan and McLoughlin, 2015; Nunkoo and Gursoy, 2016). The second body highlights collaborative planning approaches that take a critical view, looking for conflict and turning it into solutions (Almeida et al., 2017).

Local governments play an active and central role in defining and facilitating tourism strategies. Although many authors agree about the sharing of responsibility and about collaboration among the different stakeholders (De La Cruz Pulido-Fernandez and Pulido-Fernandez, 2019; Valente et al., 2015), they also highlight the fact that effective tourism management planning needs supervision from the public sector (Chiasson et al., 2019). Nevertheless, local administrations have been criticised for imposing top-down planning and decision-making, as well as incremental and short-term policy making, while lacking overall direction and coordination (Jamal and Camargo, 2018).

In order to strengthen trust and public assent, previous studies have discussed the need of private and public actors contribution to the tourism governance (Borges et al., 2014) and, at the same time, scholars have underlined the need of community participation in planning decision issues; such participation leads to more suitable and sustainable policies for the local context (Dragouni et al., 2018). With collaborative planning, the differences in knowledge and values among individuals add value to a network system aimed at building a structural dialogue to define a tourism strategy that meets the common interest (Ruhanen, 2013). In this context, there is a strong need for a better definition of a decision-making process based on multiple stakeholder involvement and, at the same time, a growing demand for tools to inform and engage citizens better.

This research, by illustrating a protocol used in Tuscany for a collaborative approach to tourism, is an attempt to fill the gap between the theory and effective solutions. While the research has continued to grow, particularly in relation to the theoretical analysis of collaboration among various stakeholders and the role of governments in tourism planning (Chiasson et al., 2019; Presenza et al., 2014), there is a scarcity of case analysis demonstrating that collaborative planning is not only an ethical way to engage citizens but is also a path to obtaining new and effective tourism planning solutions (Dragouni et al., 2018).

This study therefore analyses a practical application of stakeholder engagement in tourism planning that follows a Habermasian collaborative approach, using the case of Tuscany 2020, which is an ongoing process undertaken by the Tuscany Region to obtain a better identification of public needs, goals, strategies and policies in tourism development. This paper also contributes to the debate on stakeholder engagement in tourism policy from the perspective of public administration, by sharing experiences of inclusive tourism planning based on a tested protocol that can be replicated in other research (Petrova and Hristov, 2016). 
The paper is organised as follows. Section 2 describes the literature review, Section 3 explains the research design and Section 4 illustrates the findings. Section 5 suggests the highlights of the case study of Tuscany 2020 by testing the finding. Finally, Section 6 offers some further discussion, conclusions, and proposals for future research agenda.

\section{Literature review}

Tourism planning that follows a collaborative approach is becoming an increasingly large part of the whole long-term process. Several authors agree on the need to engage the community (Presenza et al., 2013) in order for a tourism planning process to be effective (Alrwajfah et al., 2019). Stakeholder engagement and community participation in strategic tourism planning are ways of better identifying community needs and goals to ensure sustainable processes and to foster learning among the power structures involved (Vogt et al., 2016). In turn, stakeholders bring their personal knowledge (experience, local conditions and needs) to the planning process (Del Chiappa et al., 2018).

At the same time, authors highlight the fact that the most critical and challenging issue is to select the stakeholder categories and to guarantee collaboration within them (Saito and Ruhanen, 2017). It has been stressed that procedural models of collaborative tourism planning do not alone provide adequate guidance for tourism planning and policy development (Jamal et al., 2002). There is a great risk that the planning, while well-articulated, justified and defensible, can remain a desktop exercise with little or no implementation, as the political decision is often made before the data collection is complete (Martins, 2018). Regional tourism planning supports stakeholder engagement in urban tourism strategy decisions; however, it has been noted that this aspect is difficult to realise in practice. Indeed, Saito and Ruhanen (2017) highlight the presence of a gap between gaining consensus and obtaining empirical evidence in effective managing stakeholder engagement. The points of view of different stakeholders mean that there is a general absence of a common vision. As previous scholars have discussed (Bregoli et al., 2016), the level of coordination between stakeholders represents the crucial factor for the competitiveness of a destination. In this perspective, scholars suggest selecting stakeholders according to their interests and aims and facilitating their active participation in the planning process (Bonzanigo et al., 2016; Hatipoglu et al., 2016). To achieve effective engagement in tourism planning, governments must take adequate steps to gain and take action on the perspectives and points of view of all stakeholders, and involve them in the decision-making process from the beginning (Vogt et al., 2016).

The context of tourism planning is politicised; consequently, a procedural collaborative model is required to ensure wide participation (Lin and Simmons, 2017). To operate more closely to their citizens, the top-down approach of governments in strategic planning has been displaced by a bottom-up one. By following this bottom-up approach, local communities, businesses and stakeholders in general are empowered in policy tourism decisions (Del Chiappa et al., 2018). Moreover, according to Tosun (2006), to avoid the risk of centralising the process of creating a tourism development strategy, tourism development must be shared, and significant parts of the communicative participation must be delegated to an external and super partes entity that is able to grant transparency within the process. This process requires professional actors who can facilitate interaction, stimulate stakeholders and bring together the stakeholders' different aims and values. In this context, social interaction is fundamental: a public participation process grounded on discussion and mutual learning among stakeholders interested in tourism issues leads to a high quality and effective agreement (Habermas, 1984).

The literature review highlights the challenges for tourism planning in selecting and effectively engaging stakeholders, and in defining a standard protocol for collaborative policy making. This 
research aims to illustrate the use of an experimental protocol applied by the Tuscany Region to overcome the difficulties in engaging stakeholders and to find the most effective collaborative planning, using Habermas's framework.

\section{Research design}

Methodology

The research adopts a qualitative approach and uses case analysis (Yin, 2018) with an action research approach (Collier, 1945; Lewing, 1946). According to Hall (1981) and Brown and Tandon (1983), this method can be successfully applied to participatory research by contributing to the development practical and scientific issues. According to McTaggart et al. (2017), the action research approach facilitates participants to collaborate and to achieve an ideal speech situation. In order to take fully advantage from the action research approach, the management of the meetings has to be conducted by an external entity able to link and to understand the needs of each participants - researches and practitioners - involved in the project (Erro-Garcés and Alfaro-Tanco, 2020). The case study examines how Tuscany began a collaborative tourism planning approach with its stakeholders, based on the Habermasian framework. The case study is used to analyse the strategy followed in the Tuscany Region to build a consensus. The analysis was conducted over an eight-month period from October 2018 to May 2019. The Tuscany Region is currently arranging a new collaborative planning session to collect new ideas and suggestions from stakeholders.

The research results and discussion are grounded on the experience and personal information of the authors, who played the role of lead planner for the Interuniversity Centre for Tourism Research (CIRT). According to the action research approach, the leader of the process needs to have organization and management skills (Ollila and Ystrom, 2020). During the sessions using the collaborative planning approach, information was recorded. Each observation was analysed and diffused to the stakeholders, to feed the discussion. The researchers also attended other meetings and workshops about tourism issues organised by the Region to discover stakeholders' sentiments about the whole tourism initiative. We applied the Habermas framework as set out in previous studies (Fisher et al., 1981; Innes, 1996) by defining individual steps to match the aim and timing of the planning process; by ensuring the stakeholder selection process focused on the stakeholders' interests, rather than their positions; by having a neutral expert to manage the planning discussion; and by choosing the type of communication to give stakeholders an equal voice in expressing questions, assertions, attitudes, desires and needs. Moreover, we used Jacobson's (2007) communication model to test whether Habermas's concepts of validity claims were present or absent (Burnside-Lawry et al., 2013; Burnside-Lawry and Ariemma, 2015; Burnside-Lawry and Carvalho, 2015).

\section{Data Collection}

The Tuscany collaboration with the CIRT ran from October 2018 to May 2019 and remains in progress. According to Tuscany Region's guidelines, the CIRT decided to follow a collaborative planning approach based on the Habermasian framework to reinforce dialogue and to enhance contributions to a common strategic vision by creating consensus building at the regional level. The collaborative planning helped Tuscany Region to clear the scene that political decisions could be made before data collection was complete, and that participants were faced with the task of legitimizing previous made decisions. Moreover, to avoid the risk that powerful groups can form coalitions to dominate the results, Tuscany Region appointed the CIRT to run the collaborative process as a neutral and external entity.

To spread information, the CIRT prepared memoranda and minutes, brief issue papers, and talking points for stakeholders, either on request and on their own, to help focus and move the process of 
consensus building. Within each step the stakeholders were asked to carefully present his own suggestions, proposals, etc. Solutions outlined by participants were not considered permanent, in order to avoid that temporary agreements may become a fixed part of the agreement process instead of an adaptive one. Throughout the process, the CIRT tried to maintain a high level of trust between different groups as each information was shared within the network and any efforts was made to ensure a high level of dialogue communication between the stakeholders.

\section{Data analysis}

Previous research has demonstrated that the Habermasian theory of communicative action may usefully guide organisations towards stakeholder engagement by focusing on how to achieve deliberative democracy (Burnside-Lawry and Ariemma, 2015; Burnside-Lawry and Carvalho, 2015; Wahl and White, 2017).

According to Habermas the achievement of a 'rational consensus' within a cluster on general or specific issues lies in the so-called 'ideal speech situation'. If communicative action is equal, transparent and based on unconstrained dialogue, this has been interpreted by Habermas as an ideal speech situation. This situation contributes to the stakeholders participating in a fair and equal collaborative planning process (Broadbent et al., 2010). The participants can estimate each other's points of view on the basis of motivation and objective proof alone, in a free context and without irrational influences such as either physical or psychological coercion. Moreover, all stakeholders are driven only by the aim to reach a rational consensus, and no time bounds on the dialogue are defined. In other words, in an ideal speech situation everyone has an equal chance to deduce and examine, and those who are more powerful, selfassured or of higher status do not have an unequal say.

The rules for realising an 'ideal speech situation' have been translated into validity claims made by the participants on various issues: comprehensibility, a true knowledge of the position, appropriateness and sincerity (Habermas, 1984).

The Jacobson's (2007) participatory communication model allowed us to analyse whether communication between an institution and its stakeholders is likely to increase deliberative and inclusive planning, by using a series of questions submitted to the participants.

\section{Context and setting}

According to the last Italian Strategic Plan for Tourism Development, Italy is performing greatly under its potential competitive level. Nevertheless, tourism in Tuscany plays a pivotal role (Ferrari et al., 2018) in the Italian and international market. Indeed, Tuscany, with Florence at its heart, is one of the most popular tourist destinations in the world. With a resident population of approximately 4 million people, it welcomes tourists for about 100 million yearlies.

Starting from 2010, the Tuscany Region promoted a significant new approach regarding the governance, organization, and promotion of the touristic system. Thought a new legal act (the so-called Consolidated Tourism Act, Law 86/2016), the Region designed a new model of local governance with the aim to:

- promote the coordination and integration between local authorities, regional agencies, and other public entities;

- define projects for the promotion of local touristic resources and products;

- coordinate the governance of companies and other entities. 
The reorganization of Tuscany's tourism policies and functions since January 2016 has strengthened the involvement of the local administration, which plays a key role in the development of tourism as a product, in close collaboration with Tuscany Region and Tuscany Tourist Promotion. At a regional level, tourism issues have been managed by Tuscany Tourist Promotion and Tuscany Region. The first is responsible for the promotion and the implementation of projects, and the latter uses the most important features of tourism to plan and set policies for the sustainable development of tourism, coordination of hospitality and information activities, homogeneity of the tourist offer, etc.

The new model of governance is based on the opportunity to build new forms of partnership between all local entities in order to achieve a stable competitive advantage for the destination and a model of sustainable growth. Moreover, the final goal is to strengthen the Tuscany's tourism image and to keep the destination at the top of the ranking of the most visited territory in the world.

According to Tuscany Tourist Board (2018: p. 9), the coordination between the different local actors is based on the sharing of values, resources, structures and dynamics of the market. These elements can aim the touristic sector to create a local identity from which to identify development guidelines and strategies to promote local areas.

\section{Findings}

The Tuscany 2020 steps

The 'Tuscany 2020' Habermasian approach of the Tuscany Region began on 20 October 2018 with a first exploratory meeting to which were invited a selected panel of academics, as well as private and public professional tourism organisations with strong theoretical and practical knowledge and expertise in tourism issues. Figure 1 describes the steps followed, according to the Habermasian approach.

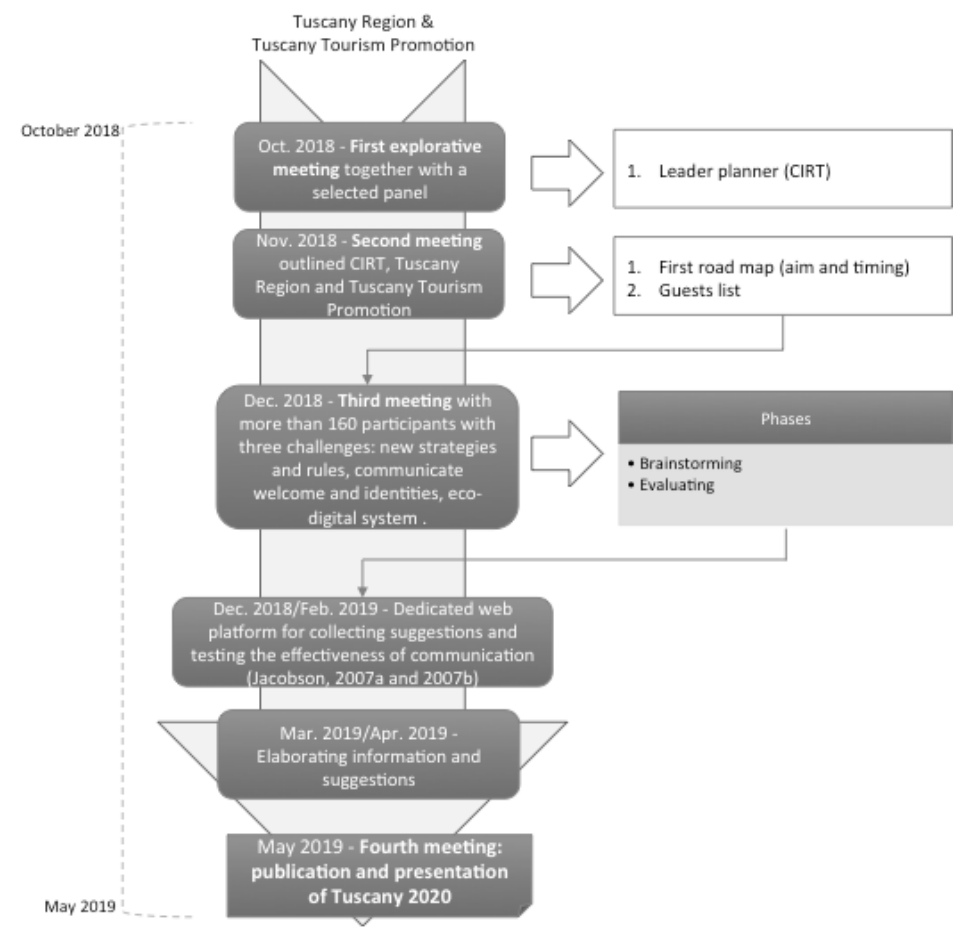

Figure 1. The Tuscany 2020 approach 


\section{The first explorative meeting}

The first explorative meeting was fundamentally held to choose, from within the selected panel, the lead planner who would guarantee the whole process by acting as a neutral, super partes, and professional figure. The external and neutral lead planner facilitated dialogue as described by Tosun (2006); employing outside facilitators for the participatory process is useful for clarifying positions and supporting participation. Matching public needs and tourism aims requires 'neutral' experts to be used to provide a pathway that avoids conflicts between the stakeholders (Almeida et al., 2017).

Thus, during the first explorative meeting (October 2018), CIRT was appointed as the lead planner. According to the guidelines of the Tuscany Region, CIRT decided to follow a collaborative planning approach based on the Habermasian framework, to reinforce dialogue and enhance contributions to a common strategic vision by building consensus at the regional level.

\section{The second meeting: the definition of the road map}

The aim of the second meeting was to define the road map for the collaborative planning approach. Using the latest data on tourism, the economy and the demographic situation, the second meeting (November 2018) analysed the main problems and selected the main local actors.

The individuation of the stakeholder boundary is a critical issue as it is frequently used as a "black box" (Iorio and Wall, 2012). Moreover, this selection is fundamental to grant bottom-up tourism planning processes, to boost active and direct participation and to assure authentic participation in decision making. Previous studies have highlighted that spontaneous participation represents an ideal mode of community participation as it provides full managerial responsibility and authority to host a community (Saufi et al., 2014; Tosun, 2006).

This model allowed the community to have a voice in the tourism development process and to be heard. At the end of this step, CIRT outlined an initial road map by separating out the aims - identifying public needs and goals in tourism development - and the timing - from November 2018 to May 2019.

\section{The third meeting: the consensus-building process step}

The third meeting, starting with the first road map drafted in the previous meeting, aimed to outline a first draft of a tourism policy based on mutual consensus and on the main priorities developed during the collaborative approach. During the third meeting (December 2018), CIRT, the Tuscany Region and Tuscany Tourism Promotion defined three challenges for discussion within a wider meeting, on the basis of the results of the first meeting. Tuscany Region invited to this second wider meeting several stakeholder's categories, such as municipalities, unions of municipalities, economic, cultural, sporting and social associations, trade unions, destination management observatory, tourism public entities, travel agencies, universities, sustainability focused nonprofit organizations, public and private research institutions, airport and port authorities, public financial institutions, and chambers of commerce (Table 1). Overall, 162 participants were involved mainly female (56\%) with a high average age next 50 years. The significant number of municipalities involved is linked to their role as they are responsible for tourism management at local level.

In this third meeting, each workgroup session was divided into two phases: 'brainstorming', which focused on future scenarios and, in particular, on a set of possible strategies and their implementation; and 'evaluating', in which the scenarios were evaluated, as were the participants' priorities and the characteristics of the implementation of the strategies. Both of these phases were based on the assumption of Habermasian validity claims: 
- $\quad$ inclusiveness - that is, each participant who can make a contribution must be invited;

- $\quad$ equal rights - that is, each participant must have the right of free expression;

- no deception - that is, everyone must speak truthfully; and

- no coercion - that is, everyone must be free to raise issues and critiques.

Table 1. Stakeholders' profile

\begin{tabular}{|c|c|c|c|}
\hline Categories & Average age & $\begin{array}{l}\text { Number and } \\
\text { gender of } \\
\text { participants }\end{array}$ & ID \\
\hline Airport authority & $25-35$ & 3 male; o female & CAo1 \\
\hline Chamber of commerce & $46-55$ & 2 male; 4 female & CAo2 \\
\hline Cultural association & $36-45$ & 3 male; 3 female & CAo3 \\
\hline Destination management observatory & $46-55$ & 1 male; 2 female & CAo4 \\
\hline Economic association & $>56$ & 10 male; 13 female & CAo5 \\
\hline Municipality & $>56$ & 22 male; 48 female & CAo6 \\
\hline No-profit organization & $25-35$ & 2 male; o female & CAo7 \\
\hline Port authority & $25-35$ & 2 male; o female & CAo8 \\
\hline Private research institution & $36-45$ & 6 male; 5 female & CAog \\
\hline Public financial institution & $36-45$ & 2 male; o female & CA1o \\
\hline Public research institution & $46-55$ & 1 male; 2 female & CA11 \\
\hline Region & $46-55$ & 2 male; 2 female & CA12 \\
\hline Social association & $36-45$ & o male; 2 female & $\mathrm{CA}_{13}$ \\
\hline Sporting association & $36-45$ & 1 male; 1 female & CA14 \\
\hline Sustainability focus no-profit organization & $25-35$ & 2 male; 1 female & CA15 \\
\hline Tourism public entity & $46-55$ & 3 male; 5 female & CA16 \\
\hline Trade union & $36-45$ & 2 male; o female & CA17 \\
\hline Travel agency & $36-45$ & 4 male; o female & CA18 \\
\hline Union of municipalities & $46-55$ & 3 male; o female & CA19 \\
\hline University & $46-55$ & 2 male; 3 female & $\mathrm{CA2O}$ \\
\hline
\end{tabular}

The brainstorming phase aimed to foster inclusiveness and equal rights through brainstorming, and each participant received accurate and complete information about the specific issues that would be discussed within the panel. The task of the panel chairman was to assure unrestricted communication based on the ideal speech conditions, that is, the freedom to speak and to introduce and question any assertion, as well as the freedom to make explicit the speaker's own feelings, aims and needs within a true and transparent discussion. The chairman explained what he or she gained from and believed about the data and the issues. According to the rules of the ideal speech situation, these interpretations could be doubted by others, and everybody could add their personal perspective. Moreover, the stakeholders were invited to give their ideas about a set of key issues regarding the panel theme. In this phase, the critical issues of each panel were discussed, with attention being paid to the content and with challenges to each stakeholder's cultural background and point of view.

The evaluation phase was focused on engendering communal understanding. Using the results of the brainstorming phase, we tried to create a mutual consensus by evaluating the participants' proposals. Two assumptions grounded this second phase. First, if equal opportunity is given to contentions on different ideas and points of view, the idea best suited to the challenge will be found. Second, a successful debate outcome requires transparent and equal rules of engagement and focuses on an 
analysis of the problem. The second phase allowed each point of view within the panel's activities to be analysed so that a common definition of the critical issues to be solved could be agreed upon. Even if it is not possible to exclude peer pressure, according to the Habermasian framework a professional lead planner can help to ensure that all interests are properly addressed. Although the stakeholders were not considering the public interest, the aim of the results was to achieve the common good because the stakeholders had many different views (Innes, 1996).

\section{The collection of suggestions within the communicative approach}

After the third meeting, the lead planner in the collaborative approach focused on communicating the first draft results to the stakeholders and, at the same time, testing the effectiveness of the protocol.

The final notes of the third meeting were shared with all participants in a plenary session and with the other stakeholders who were not present at the event. Moreover, we asked a series of questions, following Jacobson's (2007) description of a participatory model, to test the presence or absence of the ideal speech situation and to facilitate the exchange of information and the process of brainstorming about problem solving, action priorities, comments and reflections (Table 2). The test results are analysed in Section 5 .

Table 2. Themes and illustrative questions

\begin{tabular}{|c|c|}
\hline Themes & Illustrative Questions \\
\hline Context & $\begin{array}{l}\text { - What do you think is the state of the art of tourism governance } \\
\text { in Tuscany? } \\
\text { - What do you think are the main objectives of this process? }\end{array}$ \\
\hline Knowledge/Truth & $\begin{array}{l}\text { - Do you think Tuscany Region was knowledgeable about the } \\
\text { opportunities or threats to tourism planning? } \\
\text { - Do you have suggestions about opportunities and threats in } \\
\text { tourism planning? }\end{array}$ \\
\hline Appropriateness & $\begin{array}{l}\text { - Do you think Tuscany Region behaved in a manner that was } \\
\text { appropriate given its legal mandate and responsibilities? } \\
\text { - What do you think about this new governance model to define } \\
\text { tourism planning activity? }\end{array}$ \\
\hline Sincerity & $\begin{array}{l}\text { - Do you trust about the effectiveness and the fairness of this } \\
\text { collaborative planning approach? }\end{array}$ \\
\hline Comprehension & $\begin{array}{l}\text { - Do you think that the data and the rules are clearly illustrated? } \\
\text { - Do you think that the Tuscany Region understood stakeholder } \\
\text { positions and priorities in tourism planning? }\end{array}$ \\
\hline Speech Conditions: & Do you perceive that: \\
\hline $\begin{array}{l}\text { 1. Symmetrical } \\
\text { opportunities }\end{array}$ & $\begin{array}{l}\text { 1. Stakeholders were given equal opportunities to challenge } \\
\text { tourism planning policy? }\end{array}$ \\
\hline $\begin{array}{l}\text { 2. Free to raise any } \\
\text { proposition }\end{array}$ & $\begin{array}{l}\text { 2. Stakeholders were free to raise any proposal or idea they } \\
\text { whished for discussion? }\end{array}$ \\
\hline $\begin{array}{l}\text { 3. Equal treatment of } \\
\text { propositions }\end{array}$ & $\begin{array}{l}\text { 3. Tuscany Region treated stakeholder positions and/or } \\
\text { viewpoints fully and to their satisfaction? }\end{array}$ \\
\hline
\end{tabular}

In February, we closed the contribution uploads and collected the stakeholders' answers and suggestions. Lastly, we compiled the final results of our collaborative planning by separating out the strategies, actions and objectives. 


\section{The fourth meeting: the launch of Tuscany 2020 plan}

The Tuscany 2020 plan was published in May 2019 on the regional platform, and it has become a continuous stimulus for debate through the exchange of ideas and proposals both for updating it and for creating subsequent editions. To this end, open and continuous digital communication systems have been identified that allow the sharing of information, ideas and lines of action for sustainable tourism development. Consensus building and the spread of strategies have no defined borders in space, time or participation: they evolve and adapt according to new needs and aims. Stakeholder engagement is a continuous cyclical management process, and participants must remain in touch to retain an accurate overview of the ongoing process. The web-platform system helps to establish an ongoing dialectical process to steer the plan and adjust it according to stakeholders' need and aims.

\section{Highlights: The test of the ideal speech situation}

According to Jacobson (2007), it is necessary, in order to evaluate the efficacy of communicative action, to test it by asking the participants if they attribute validity to the truth, appropriateness, sincerity, and comprehension of the planning debate, and, conversely, if they doubt the validity of these issues. We adapted Jacobson's model by selecting five issues to discover whether or not Habermas's concepts of validity claims were present, and one issue to do the same for the ideal speech situation. These issues were Context, Knowledge/Truth, Appropriateness, Sincerity, Comprehension, and Speech Conditions. The test was useful not only to spread information but also to verify whether the participants felt engaged in, and trusted the equity of, the process. We analysed whether they thought they had equal opportunities to challenge the debate, whether they felt free to propose solutions and options and whether they thought that, once they had raised a proposal, they were treated equally.

\section{Context}

In evaluating the context, stakeholders brought to bear their personal knowledge and experience, and they were better able to identify community needs and goals. They highlighted the complexity of policy planning but, at the same time, agreed on the pivotal role of public administration. With reference to the main objective, they generally underlined the necessity of investing more financial resources in tourism; however, each participant suggested different ways, mainly linked to his or her own specific sector. The stakeholders also urged the spread of more homogeneous policies throughout Tuscany to produce more wealth and employment:

The main aim is to consider tourism a cross sector resource with strong investment during the next years, as we believe it is the only sector destined to grow and be able to produce wealth and employment. (CAO2)

Another common element was the diffused pessimism about the future and the ability to exploit the cultural, natural, religious and heritage resources of the Tuscany Region. However, the stakeholders were not able to identify specific attributes or conditions to overcome these challenges, and they focused on financial issues:

Our brainstorming and collaborative planning will be translated into an action plan, but who will be able to assure us that we are not wasting our time? Who can assure us that this plan will receive specific and sufficient funds to be realised? (CA05)

\section{Knowledge/Truth}

In a collaborative dialogue, the main task of planners is to diffuse knowledge through discourse and discussion, and to be aware that the long experience and praxis of each participant is a fundamental 
block to the whole public policy process (Vogt et al., 2016). With reference to opportunities in tourism planning, the stakeholders highlighted the benefits of community engagement:

The active engagement in planning and implementation of community groups facilitates the effectiveness, as we believe this plan is the consequence of the stakeholders' needs, interests and expectation. (CAo6)

Regarding the threats to tourism planning, the participants suggested that the organisation and collaboration between public and private actors should be improved:

We feel the need to encourage more collaboration between the public and private sectors in destination management issues, and the latter must contribute financially to public initiatives. (CA16)

Another threat to tourism planning underlined by the stakeholders was connected to training:

We believe that this model, to be effective, requires a significant effort in improving skills in analysing the context in order to better solve and respond to complex tourist problems and needs. (CAo3)

\section{Appropriateness}

The results showed a virtuous circle in stakeholder engagement for tourism development in Tuscany. Stakeholders, in general, appreciated the methodology; they felt engaged, and joined the meetings with interest. However, the main difficulty was related to maintaining a high level of attention among the stakeholders:

We appreciated this model of interacting with stakeholders, as we believe that taking care of all points of view, equalising knowledge and data between different stakeholders and creating conditions within the group to be apprised of the importance of this process is a fundamental element in creating effectiveness and fair solutions. (CAo6)

We like this multi-way interaction, not only between stakeholder and Region, but also among stakeholders. However, we need more digital interaction, more information flows through networks and participants. (CAo4)

\section{Sincerity}

The results confirmed those of previous studies, as a collaborative approach emphasises policy accountability and increases trust in public organisations (Wahl and White, 2017). However, the results also highlighted a widespread distrust of the effectiveness of tourism policies, and a feeling that the resources would not be sufficient for the public aims:

The context of tourism planning is politicised and characterised by a short-term view. In our opinion, tourism policies follow one another according to different political parties, and the risk is that what we are going to decide about policies could be abandoned or underfunded within the next few years. Who is able to assure us that our efforts will not be fruitless? (CA17)

\section{Comprehension}

The results indicated that an extensive stakeholder engagement process can encourage broad representation and trust that stakeholders' interests will be addressed in public policies. The clear rules and neutral lead planners fostered cooperation among the stakeholders and strengthened the sense of 
belonging to a unique community. In other words, the collaboration was intended to overcome conflicts by creating a shared consensus, and the ideal speech situation was a pivotal condition for putting everything on the table and enabling fair and equal challenges. The results highlighted the level of attention given by stakeholders to tourist issues, and they emphasised that the Tuscany Region was often weak in understanding tourists' needs:

To work out effective tourism policies, it is fundamental to put ourselves in the tourist's shoes. The typical tourist does not know the territory or the culture, but he decided to spend his time and money in a specific destination. We believe that the first assumption in good policies is respect for the tourist. (CA13)

The results also revealed a widespread scepticism about the capability of the Tuscany Region to understand the priorities of tourism planning activities, as the stakeholders noted the weaknesses in its investments:

Territory connections and accessibility are fairly difficult, and we need a huge investment in infrastructure. (CAo1)

We need innovation in the digital tourist ecosystem that enables the governance of the destination to manage digitisation and promotion of the tourist offer. (CAog)

According to the quotations, the starting point for improving our approach can be identified as the interaction between the players, which is a central element of planning (Innes and Booher, 2015). Communication is not only a channel for spreading policies but is also a form of interaction within a network and includes other stakeholders - both public and private. Even if each participant works to achieve its own interests, the results suggested that the interaction enriches the discussion and opens people's minds to searching for the best long-term solutions.

\section{Speech Conditions}

The literature recognises that ideal speech situations and effective communicative actions are rare (Fryer, 2011).

During Tuscany 2020, all the stakeholders were engaged, informed and dealt with in the same way, and none had more attention or influence than others in the decisions. The stakeholders, in general, felt satisfied with the above-mentioned speech conditions, as they believed that they had equal opportunity to make proposals and to be heard by the Tuscany Region. Even if the stakeholders believed that adversarial conflicts are wasteful, they noted that such conflicts also present potential advantages when they raise public awareness and understanding:

We believe that stakeholder engagement and community participation in this planning process have been conducted by giving equal opportunities to all categories. (CAo6)

We appreciated this new governance and each of us can learn new ideas and become able to recognise that other's views are legitimate within a constructive and fair dialogue. (CAo3)

However, even if the stakeholders perceived that there had been equal opportunities and treatment in the speech conditions, they also believed that the process of collaborative tourism planning must involve rules for financing tourism actions: 
We appreciated this new governance model as it gave us the possibility to participate and spread our opinions and proposals in a wide context; however, we would also like to discuss rules about partnerships and funding. We also need to share our opinion about the way to finance the policies we are going to define during this process. (CA17)

\section{Discussion and conclusions}

Habermas provides a guidance - a protocol for fostering communicative action - that is mainly based on the importance of communicative planning, by highlighting the rules for creating an ideal speech situation. In this study, we describe a case study to improve the engagement in a collaborative approach. Collaborative planning does not propose guidelines or handbooks for communicative action practice, as it highlights that each communicative process has its own tailor-made path based on stakeholders' interaction within a public-private network. However, this case study provides an opportunity to identify critical issues, advantages, and strategies for engaging stakeholders. The results confirm previous researches as the Habermasian theory is a useful guide for organizations to gain stakeholder engagement as the unconstrained dialogue produces consensus, and it is able to spread alternative points of view. Moreover, points of views and conflicts also produced a range of positive outcomes as they enhance tolerance, innovation and mutual learning. For these reasons, conflicts resolution and mediation must be considered as an integral component of the sustainable tourism development. According to the results, the role of local governments in tourism planning is facilitated by following a collaborative approach suitable for achieving effective public participation and for involving stakeholders in the decision-making process by considering social, economic, cultural, and others multidimensional elements fundamental to embrace crucial decisions. Moreover, the results confirm the efficacy of the choice of a third part "project leader" the CIRT in order to overcome the politicization of the process by granting neutral coordination between stakeholders aims and needs.

Tuscany implemented a bottom-up approach to engaging stakeholders in tourism planning. We believe that sharing experiences, ideas and solutions is the best way to solve problem planning: each point of view is useful to solve the planning puzzle. The case of Tuscany 2020 focused on building a consensus by creating an equal and open space based on equal interaction between the public administration and the stakeholders. In addition, a pivotal part of this planning process was to share knowledge and mutual understanding by finding a 'common denominator' among the aims of the different stakeholders. Our experience, based on the principles of communicative action, shows the logical steps of reaching a wide base of participants, sharing points of view fairly in a collectively organised brainstorming process, and improving the effectiveness and sustainability of tourism planning.

We also contribute to the debate on stakeholder engagement in the tourism planning issue from the side of the public administration, by sharing an experience of inclusive participation based on a Habermasian approach. In this sense, participants are oriented toward developing a mutual understanding and not just achieving some specific purposive results through the interaction. However, the results also highlight the difficulties in gaining consensus related to economic issues: financial resources are limited and are not sufficient to achieve all of the goals proposed by the stakeholders. Even if the participants appreciated the new governance of the Tuscany Region, they did not entirely trust the mechanism: they were worried about the continuation of the process, given its close link with regional political issues. This approach can be interpreted as a possible solution to the bureaucracy problem: the stakeholders suggested that the rules in the tourism sector should be simplified and clarified, while greater engagement came close to the stakeholder needs and generated more effective bottom-up policies. 
Our study has twofold theoretical practical and implications. From a theoretical point of view, the results contribute to feed the policy maker's perspective as we determined a protocol, made up by subsequential logical steps in order to better dig the problem and to fairly engage stakeholders. Even if each tourism destination is affected by its own elements, the logic path of this strategic planning protocol could be adapted to other destinations. The practical implications of the study focus on stakeholders' perspective as we identified the role that they play in collaborative tourism planning and the way in which they can be involved. The results, by highlighting the main critical issues for each category, suggest to policy makers how to manage the different groups. More in deep, the realization of the "ideal speech situation" is very difficult and may be undermined by the threatens highlighted in the study, such as the lack of financial resources, the claim to more homogeneous policies to increase tourism trends, the need to improve trust and collaboration between public and private, the difficulties in maintaining high level of attention and the widespread scepticism about the capability of public entities to understand priorities in defining tourism policies. Public entities have to consider these critical issues and must fill the gap in order to come as closer as possible to a fairly and unconstrained dialogue, and to gain stakeholders' engagement.

This study has several limitations. The first is that the case represents only the first experience of applying a Habermasian approach to collaborative tourism planning, and, as this has been an ongoing process, we need further feedback in order to evaluate its effectiveness. Moreover, this Habermasian approach for collaborative planning should be tested for another destination. The third limitation is that we interviewed stakeholders during the process but did not do so afterwards, and we believe that it would be useful to gain further information about their level of engagement and trust within the project. A further step may involve asking stakeholders whether they still feel engaged and unconstrained within the debate, to demonstrate the respect for Habermas's rules of an ideal speech situation.

Further research is necessary to improve our results by enlarging the population of the study and enriching our findings through interviews to gain a better understanding of the commitment of local public actors and stakeholders in achieving an ideal speech situation to encourage clear and unconstrained communicative action.

\section{References}

Almeida, J., Costa, C., \& Nunes da Silva, F. (2017). A framework for conflict analysis in spatial planning for tourism. Tourism Management Perspectives 24, 94-106.

Alrwajfah, N. M., Almeida-Garcia, F., \& Cortés-Macias, R. (2019). International aid to tourism planning and stakeholder participation in the Petra region. Cogent Social Sciences 1(5), 1-21.

Bonzanigo, L., Giupponi, C., \& Balbi, S. (2016). Sustainable tourism planning and climate change adaptation in the Alps: a case study of winter tourism in mountain communities in the Dolomites. Journal of Sustainable Tourism 24(4), 637-652.

Borges, M.R., Eusébio, C., \& Carvalho, N. (2014). Governance for sustainable tourism: a review and directions for future research. European Journal of Tourism Research 7(1), 45-56.

Bregoli, I., Hingley, M., Del Chiappa, G., \& Sodano, V. (2016). Challenges in Italian wine routes: managing stakeholder networks. Qualitative Market Research: An International Journal 19(2), 204224 .

Broadbent, J., Laughlin, R., \& Alwani-Starr, G. (2010). Steering for sustainability. Public Management Review 12(4), 461-473.

Brown, L.D., \& Tandon, R. (1983). Ideology and political economy in inquiry: action research participatory research. Journal of Applied Behavioral Science 19(3), 277-294. 
Burnside-Lawry, J., Lee, C., \& Rui, S. (2013). Habermas and the Garants: narrowing the gap between policy and practice in French organisation-citizen engagement. Communication, Politics $\mathcal{E}$ Culture 46, 155-176.

Burnside-Lawry J., \& Ariemma L. (2015). Global governance and communicative action: a study of democratic participation during planning for the Lyon-Turin high-speed rail link. Journal of Public Affairs 15(2), 129-142.

Burnside-Lawry, J., \& Carvalho, L. (2015). Building local level engagement, in disaster risk reduction: a Portuguese case study. Disaster Prevention and Management 24(1), 80-99.

Chiasson, G., Angelstam, P., Axelsson, R., \& Doyon, F. (2019). Towards collaborative forest planning in Canadian and Swedish hinterlands: different institutional trajectories? Land Use Policy, 83, 334-345.

Collier, J. (1945). Social research/an international quarterly of social science. New York: Graduate fac.

De La Cruz Pulido-Fernandez, M., \& Pulido-Fernandez, J. I. (2019). Is there a good model for implementing governance in tourist destinations? The opinion of experts. Sustainability 11, 1-21.

Del Chiappa, G., Atzeni, M., \& Ghasemi, V. (2018). Community-based collaborative planning in islands: a cluster analysis in the context of Costa Smeralda. Journal of Destination Marketing $\mathcal{E}$ Management 8, 41-48.

Dragouni, M., Fouseki, K., \& Georgantzis, N. (2018). Community participation in heritage tourism planning: is it too much to ask? Journal of Sustainable Tourism 26(5), 759-781.

Erro-Garcés, A., \& Alfaro-Tanco, J.A. (2020). Action research as a meta-methodology in the management field. International Journal of Qualitative Methods 19, 1-11.

Ferrari, G., Mondejar Jiménez, J., \& Secondi, L. (2018). Tourist' expenditure in Tuscany and its impact on the regional economic system. Journal of Cleaner Production 171, 1437-1446.

Fisher, R., Ury, W., \& Patton, B. (1981). Getting to yes. New York: Random House Business Books.

Fryer, M. (2011). Facilitative leadership: drawing on Jürgen Habermas' model of ideal speech to propose a less impositional way to lead. Organization 19(1), 25-43.

Habermas, J. (1984). The theory of communicative action: Vol. I: Reason and rationalization of society. London: Heinemann.

Hall, B. L. (1981). Participatory research, popular knowledge, and power: a personal reflection. Converge 14(3), 6-19.

Hanrahan, J., \& McLoughlin, E. (2015). A framework for analyzing the local authorities tourism planning in Ireland: a socio-cultural perspective. European Journal of Tourism Research, 11, 73-86.

Hatipoglu, B., Alvarez, M. D., \& Ertuna, B. (2016). Barriers to stakeholder involvement in the planning of sustainable tourism: the case of the Thrace region in Turkey. Journal of Cleaner Production 111, 306-317.

Innes, J. E. (1996). Planning through consensus building: A new view of the comprehensive planning ideal. Journal of the American Planning Association 62(4), 460-472.

Innes, J. E., \& Booher, D. E. (2015). A turning point for planning theory? Overcoming dividing discourses. Planning Theory 14(2), 195-213.

Iorio, M., \& Wall, G. (2012). Behind the masks: Tourism and community in Sardinia. Tourism Management 33, 1440-1449.

Jacobson, T. L. (2007). A case for the quantitative assessment of participatory communication programs. Paper presented at International Association for Media and Communication Research Conference, Paris - France.

Jamal, T., Stein, S. M., \& Harper, T. L. (2002). Beyond labels: Pragmatic planning in multi-stakeholder tourism-environmental conflicts. Journal of Planning Education and Research 22, 164-177.

Jamal, T., \& Camargo, B. A. (2018). Tourism governance and policy: whiter justice? Tourism Management Perspectives, 25, 205-208. 
Lewin, K. (1946). Action research and minority problems. In G.W. Lewin (ed.) Resolving social conflicts. New York: Harper \& Row.

Lin, D., \& Simmons, D. (2017). Structured inter-network collaboration: public participation in tourism planning in Southern China. Tourism Management 63, 315-328.

Martins, M. (2018). Tourism planning and tourismphobia: an analysis of the strategic tourism plan of Barcelona 2010-2015, Munich Personal RePEc Archive, Paper No. 88203. URL: https://mpra.ub.unimuenchen.de/88203/1/MPRA_paper_88203.pdf (accessed on 18.11.2019).

McTaggart, R., Nixon, R., \& Kennis, S. (2017). Critical participatory action research. In Kemmis, S., McTaggart, R., Nixon, R. (eds.). The action research planner. Doing critical participatory action research. New York: Springer.

Nunkoo, R., \& Gursoy, D. (2016). Rethinking the role of power and trust in tourism planning. Journal of Hospitality Marketing and Management 25(4), 512-522.

Ollila, S., \& Ystrom, A. (2020). Action research for innovation management: three benefits, three challenges, and three spaces. RED Management 50(3), 396-411.

Petrova, P., \& Hristov, D. (2016). Collaborative management and planning of urban heritage tourism: public sector perspective. International Journal of Tourism Research 18(1), 1-19.

Presenza, A., Del Chiappa, G., \& Sheehan, L. (2013). Residents' engagement and local tourism governance in maturing beach destinations. Evidence from an Italian case study. Journal of Destination Management \& Management 2(1), 22-30.

Presenza, A., Micera, R., Splendiani, S., \& Del Chiappa, G. (2014). Stakeholder e-involvement and participatory tourism planning: analysis of an Italian case study. International Journal KnowledgeBased Development 5(3), 311-328.

Ruhanen, L. (2013). Local government: facilitator or inhibitor of sustainable tourism development? Journal of Sustainable Tourism 21(1), 80-98.

Saito, H., \& Ruhanen, L. (2017). Power in tourism stakeholder collaborations: power types and power holders. Journal of Hospitality and Tourism Management 31, 189-196.

Saufi, A., O’Brien, D., \& Wilkins H. (2014). Inhibitors to host community participation in sustainable tourism development in developing countries. Journal of Sustainable Tourism 22(5), 801-820.

Tosun, C. (2006). Expected nature of community participation in tourism development. Tourism Management 27(3), 493-504.

Tuscany Tourist Board (2018). Tuscany Regional Survey. Retrieved from: www.toscanapromozione.it/ uploads/documenti/1-Tuscany Regional Survey Gent.pdf (accessed on 11.7.2020).

UNWTO (2019). Tourism highlights. Madrid: World Travel Organization.

Valente, F., Dredge, D., \& Lohmann, G. (2015). Leadership and governance in regional tourism. Journal of Destination Marketing and Management 4(2), 127-136.

Vogt, C., Jordan E., Grewe, N., \& Kruger, L. (2016). Collaborative tourism planning and subjective wellbeing in a small island destination. Journal of Marketing E Management 5(1), 36-43.

Yin, R. K. (2018). Case study research: Design and methods. Thousand Oaks, CA: Sage.

Wahl, R., \& White, S. K. (2017). Deliberation, accountability, and legitimacy: a case study of policecommunity forums. Polity 49(4), 489-517.

Received: $31 / 01 / 2020$

Accepted: 20/10/2020

Coordinating editors: Giacomo Del Chiappa and Anestis K. Fotiadis 